at the lower part of the lung; friction-sound wes beard towards the front, and bronchial breathing down to the extreme base.

June 8th. He complained of littlo pain. The dulness and bronchial breathing still remained. Ho had expectorated some very adbesive sputum. He was ordered to take the mix. ture three times a day; to have a blister to the left side; and to take ordinary diet, and four ounces of wine daily.

June 0th. The antimonial was omitted, and a mixture with ammonia and squills substituted. He progressed steadily from day to day; and was discharged well on the 26th.

[To le continued.]

\section{OBinginal Communications.}

\section{SCROFULOUS DISEASES OF THE EXTERNAL LYMPHATIC GLANDS :}

THEIR NATURE, VARIETT, AND TREATMENT.

By P. C. Price, Esq., Surgeon to the Great Northern Hospital; the Netropolitan Infirmary for Scrofulous Children

at Margate; etc.

Mavy disordered conditions, which involve the absorbent glands from infancy to advanced manhood, have been described by the majority of both ancient and modern writers as partaking of the nature and characters of scrofula.

In considering these so-called scrofulous affections, I shall attempt to classify them in such a way as to shew the utility of an arrangement, which more readily enables the practitioner not only to form a tolerably correct impression as to the nature of the diseased action, but to adopt a line of treatment best fitted to bring individual cases to a successful termination.

Before further approaching the consideration of a subject accompanied with some slight difficulty, it may perhaps be ad. visable to attempt to define the meaning of two sister terms, scrofulous and tuberculous, which are oftentimes of no very clear appreciation, and to inquire how close a relationship, so fur as morbid conditions of the absorbent glands are concerned, exists between them.

At a very early period in the history of medicine, the terms xoupases, scrofula, and struma, were employed to designate certain enlarged and diseused conditions of the lymphatic glanik, especially those situated in the region of the neck. As the study of disease advanced, and the pathology of morbid conditions of the system became better understood, the above terms acquired a more comprehensive signification. The ex tended views of many able observers, and particularly those of Wiseman, expounded over two hundred years ago, opened the cyes of practitioners to the importance of considering other diseases, not hither included, as partaking of the scrofulous type. Since this period, additional experience has more fully propounded the extended meaning of an appellation which unfortunately, is compelled to be almost of hourly use and im. portance to those whose professional pursuits are carried on among both the rich and the poor of civilised nations.

In this country, scrofuln or struma is very generally em. ployed to signifj, to use the words of a well known modern writer, " a state of constitution distingrished in somo measure by peculiarities of appenrauce even during health, but much more by peculiar liability to certain diseases, including pul monary phthisis." (Paget's Lectures on Surgical Pathology.) The chief of thesc diseases are various abnormal conditions of the lymphatic glands; of the skin ; of cellular, mucous, and other tissues; of the bones, joints, synovial and other membrunes; of various organs, such as the eye, liver, kidney, testicle, breast, etc.; and, indeed, of alwost every tissue and organ which com. pose the body.

The chief patbological chnnges which ensue in these so.called scrofulous diseases are die to an abnormal tendency to admit a more or less modified process of inflammation, ulceration, and suppuration, influenced in lind and degree by peculiarities of constitution induced by certain artificial means, such as indifferent nourishment, bad ventilation, and various unwholesome influences, and capable of transmission from parents to offspring. But the term scrofula is, moreover, used (whether judiciously is a point for consideration) to include such affections, occurring in individuals who more or less plainly exhibit a certain unmistakeable diathesis, which consists in the deposition of a special morbid material termed tubercle.
The frequenoy with whioh tuberenlows depositions are found constituting, or alosely associating with, 80.called scrofulons affections, is amply sufficient to show bow very difficult it is always to define the exact meaning of scrofula or scrofulous diseases, without including those affections in which tubercle plays an important part.

Hence it must appear that, while scrofulous or strumons affections of various organs and tissues frequently consist in a development of tubercle, there are, nevertheless, numerous occasions in which, so far as observations extend, no such perceptible condition obtains; and, therefore, the term scrofulous must sometimes, if not always, be employed to include both tuberculous and certain non-tuberculous affections, and be generally accepted in that comprehensive way, which usage and the want of a more definite phraseology have assigned to it.

Nevertheless, attempts bave been made to distinguish with greater accuracy those diseases which ore strictly scrofnlous, and those which depend on a special tuberculous deposition. M. Lebert has writton fully and ably on this point, and endeavours to prove that such a distinction can in general be drawn, and applied with advantage to their appreciation and management.

Limiting the consideration of this important question to certain forms of so-called scrofulous disease of the absorbent glands, it will be seen how far consistent the observations now offered are with the results of practical experience.

The morbid slterations, both of structure and function, which the external absorbent lymphatic glands are prone to undergo in scrofulous constitutions, may, without regard to relative frequency, be classed under the following heads :-

I. Acute, Subacute, and Chronic Inflammation, or Lymphadenitis.

II. Chronic Enlargement, or Simple Hspertrophy of Struc. ture, independent of Vascular Derangement.

III. True Tuberculous Alterations.

Before discussing, however, these various morbid conditions, it may be well to inquire to what extent the absorbent ressels, so intimately associated with the glands, are liable to be included in inflammatory and other disturbances apt to arise in a scrofulous habit of body.

It will be seen, when treating of the various diseased conditions to which the external absorbent glands are susceptible, that very acute intlammatory disturbance is, as a rule, an infre. quent complication in strictly scrofulous habits. The same rule holds good as regards the absorbents; for they seldom exhibit well marked inflammatory excitement of an exalted type, although under lesions not strictly idiopathic considerable irritation, and inflammation itself, may obtain, even though the strumous diathesis be prominently portrased.

In subacute or chronic forms of glandular enlargement, arising from systemic disturbance or local irritation, the connective lymphatics do not frequently show any marked sign of implication. In truly scrofulous and tuberculous diseases, the lymphatic tracts are, however, more often the seat of morbid alterations. Such affections are, it would appear, the result of absorption, and not of independent deposition; for, as a rule, the lymphatics situated in close relationship with a tuberculous gland, are more liable to be included in similar action than those more remote.

A scrofulous condition of the valves of the absorbents bas been described, but has only lieen detected on a post mortem examination; so that, in all probability, its existence is fraught with little real danger or inconvenience. In the lacteal system of absorbents, however, scrofulous and tuberculous depositions are of vers common occurrence; and their preseuce oftentimes seriously complicates, and, in a manner, causes an important and fatal disease-tabes mesenterica.

I.-Infladiyatory Conditions of the External Lydiphatic Glands is Scrofulots Subjects.

Acute Infiammation. It has alrealy been observed that truly acute inflammation of the lymphatic glands in individuals pos. sessing a scrofulous tendency is comparatively rare; although Wiseman and other experienced anthors have related instances of its occurrence. liveryday experience, however, tends to prove that a more or less modified inflammatory action is very prone to invade the superficial absorbent glands; but such dis. turbance, as Hunter has clearly pointed out, is greatly controlled by the existence of a special diathesis. When acute inflamma. tion does incolve one or more portions of the external glandular system in scrofulous subjects, it may occur under two distinct conditions; either as an apparently idiopathic affection, or as a secondary or consecutive coincidence. 
The glands most exposed to the invacion of more or lees Thto inflummatory disturbance, arising as a specific affection, coute intammath which by situation are rendered susceptible to the are those which by situation vicissitudes of temperature, injuries, eto., combined with an inherent disposition to functional juries, etco, combined with an inheres it is that the glands of the neck, froe, and head, are much more frequently the seat, the neck, simple inflammation, but of more complicated affecnot only of simple infiammat suggest, is borne out by practice. More than tiro-thirds of the enses of idiopatbio glandular in flammatory disturbance which I lave seen, and from the statistics flammatory disturhance which confined strictly to those glands situsted above the shoulders, and especially to those placed situated abore the angle of the lower jaw, and consequently ex. posed to atmospheric and other injurious influences.

porildren, and infants of a delicate constitution, exhibiting at this early period, perhaps, no very decided scrofulous tendency save a period, seraspicions conformation. 'The first local symptom which attracts the attention of the mother or nurse to the existence of any mischief taking place, is a slight swelling, and perhaps hest and redness of the part, with tenderness to the tonch. The swelling and pain, at first comparatively trivial, inch. constitution, probably already dehilitated, and perchance asso. ciated with more manifest scrofulous disease, begins to suffer. The pulse quickens; more or less irritative fever succeeds ; the tongue is furred; the bowels are costive; and the urine scanty, and snturated with lithates. It may be that the intlammatory action is coitined to the gland; but, if the symptoms advance, it is more than probable that the cellular bed in which the gland reposes becomes affected, and at an early date shows evidence of implication. Should the vascular excitement not overstep the bounds of serous or fibrinous exudation, little looal destruction will have resulted. The effused fluid is absorbed; and the lymph is either taken up, or becomes more or less consolidated and organised, giving to the gland an indurated appearance. But, as just observed, the irritation, commencing in the gland, is very apt to be extended to the cellular tissue in which it lies. Indeed, the liability of this loose surrounding structure to adopt the inflammatory tendency is so great, that often a very wholesale destruction takes place. The extension of the swelling and pain which usually accompany adenitis is, as a rnle, principally owing to the inclusion of the tegumentary and cellular tissues.

The following woodent, from a patient aged 15, under my care at the Hospital, well illustrates this condition.

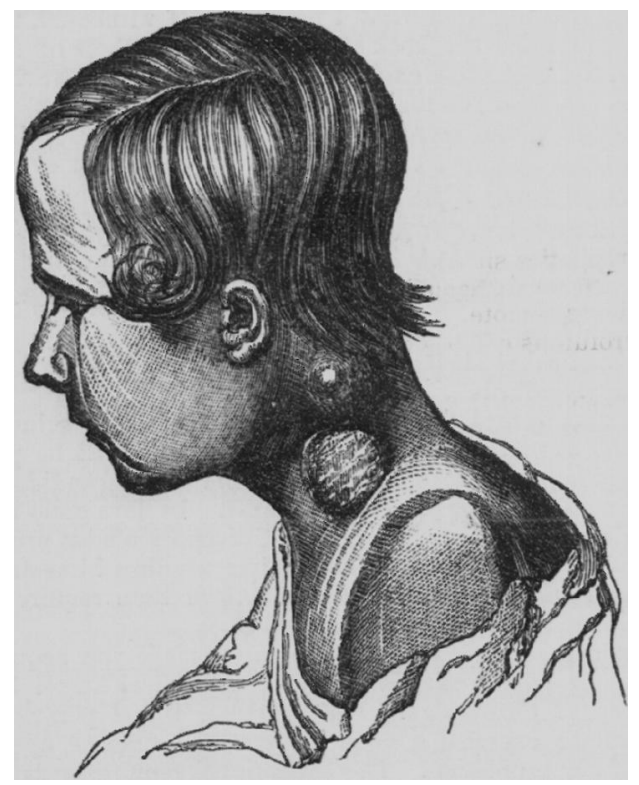

Fig. 1.

Suppuration of a gland, the sequel of idiopathic inflammution in such subjects as now claim attention, is, I believe, of comparatively infrequent occurrence; and, although the formation of abscess results from such a condition, still it is not always situated in the proper glandular structure, but sometimes in the cellular tissue by which it is surrounded.

A recognition of this fact is essential; for, while suppuration of an absorbent gland is ofton a todious and complicatod pro. cess, that of the cellular tissue, especially when limited, is less cerious, and more easy of management. There are cases, howerer, in which both the inflamed gland and its coverings are freely involved in inflammatory lesions, and readily pass on to suppuration.

Although, for the sake of illustration, the changes which obtain from acute inflammatory causes have been described as limited to a single gland, yet, as is well known, tro, three, or even an entire chain or clump may be, either at the same time or in succession, involved. 'This is by no means unfrequently the case; for, owing to the conglomerate arrangement of the gland-clusters, especially about the neck and armpit, it is rare to find the mischief confined mercly to a single meniber of a numerous community.

Secondary or Consecutive Infiammation. Acute inflammatory conditions of the lymphntic glanils, occurring as secondary or dependent affections, are unusual. Such disturbance may, however, obtain from any direct lesion of neinisbouring parts, and follow as a sequent of poisonous absorption. It is rare, however, in very scrofulous subjects, to find such condition result from irritation; and, even when it does occur, it is often fourd devoid of some essentinls which constitute exalteil in flammation. I have occasionnlly seen, in strictly scrofulous children, active inflammation of the absorbent glands, consequent on the occurrence of fevers and other debilitating influ. ences: but, while a subacute or chronic form is very common, that of a more acute nature is imuch less general.

When such exalted inflammation attucks the absorbent glands, there exists little or no distinctive difference letween it and that which obtains idiopathically, or apparently so, and consequently the foregoing observations are equally applicable. It must, however, be remembered that, when secondary acute inflammatory lesions of the lymphatic ganglia do obtain in scrofulous individuals, either as accompaniments or scquents of other diseases or injuries, they are more or less modified by the existence of the constitutional dinthesis.

Recognition. The only affection which, I think, is liable to be confounded with acute inflammatory lesions of the external lymphatic glands, is limited inflammation of the cellular tissue. Some difficulty is often experienced in arriving at a correct apprecistion on this point; and few surgeons of much experience will undertake to say, on numerous occasions, in which structure the primary mischief has commenced, when both the gland and its cellular bed are included in the inflammatory disturbance. As a rule, however, it is probable that when any swelling, heat, and tenderness exist in the tissues in the neighbourhood of absorbent glands, the original mischief commenced in one or more of the lymphatic organs; and should early attention have been directed to these alterations, a positive indication of the exact seat of lesion will be casily obtnined. The affected gland or glands may be found enlarged, more or less globular in form, and senielastic to the touch, althongh the covering tissues be more or less swollen, puify, and painful.

Besides the above local indications, there will exist considerable systemic derangement; and, perhaps, a more or less perfect history of an innate tendency to lymphatic disease may be establisbed.

Pathological Changes. From whativer cause tho lymphatic ganglia become acutely inflamed, the morbid changes which ensue are identical in kind, though moditied in degree. Swelling, as previously stated, is the earliest symptom which directs attention. It is oving, it would appear, to a swollen condition of the gland jtself, which results firom more or less general increased vascularity, and the subsc'quent serous infiltration of its parenchymatous tissue. The nature of the exudation, however, which takes place, is dependent on the degree and extent to which the inflammation reaches. Should the gland be acutely inflamed, its areolar structure may not only become highly injected, but extravasated with blood. When the exudation is simply serous, it may be absorbed; and the local inflammation being reduced, the gland soon returns to its normal condition.

Should the effusion that takes place be fibrinous and plastic, the gland is apt to become more or less solidified; absorption may, however, entirely remove all trace of the plastic material; but, should such not occur, the gland remains more or less permanently indurated, with its functions, perhaps, only partially interfered with. 'The plastic exudation thus thrown out, however, is occasionally so extensive that the normal glandular however, is occasion considerably atrophied or displaced, so that the true character of the affected organ is irretrievably de. strojed. Lymphatic ganglia liave been shewn to retain their 
function, oven when extensively involved in inflammation; and, although the tabular arrangement may be included in tho general disturbance, still total destruction is not a frequent occurrence.

When inflammatory action has passed bejond the stages of serous and plastic exudation, it is apt to advance to suppura. tion. The formation of abscess necessarily involves, more or less, the integrity of the entire gland, and leads to its entire destruction.

The character of the purulent fluid is modified in accordance with the specific diathesis of the individual in whom it occurs. If the strumous habit be well marked, the pus will bear certain indications, which may at once distinguish it from that which obtains in abscesses occurring in constitutions not perceptibly tainted. Should the patient be delicate and of wasted porvers, the secretion will often be found devoid of those characters which constitute thick and healthy pus. If the scrofulous habitus be prominent, mingled with the purulent matter will be found shreds of degenerated and withered lymph, more particularly to be described when adverting to more marked scrofulous suppuration of glands.

Although such outward changes as above alluded to may involve one or moro glands, still, as before observed, it is seldom that the inflammatory mischief is limited to the glandular structure. The cellular bed in which the affected organ reposes, generally very early shows signs of implication. When the vascular excitement is not very extensive, the gland merely becomes glued to the cellular structure by which it is sur. rouuded; but, if the inflanmatory process proceeds, the formation of pus may lead to a definito secreting surface being esta. blished. The great tendency exhibited by the cellular tissue, so intimately associated with an affected gland, to partake in the vascular derangement, has been well illustrated by $\mathrm{Mr}$. Goodlad, in an able treatise published many years since ( $O n$ the Diseases of the Absorbent System, etc., 1814).

[To be continued.]

\section{Cransaxtions of 迎ramethes.}

\section{LANCASHIRE AND CHESHIRE BRANCH.}

\section{PRESIDENT'S ADDRESS. \\ By M. A. Eason Wiu.kinson, M.D., Manchester. [Delirerel .June 2:th, 1860.]}

IT has been usual, I believe, on similar occasions to this, to give a retrospective glance at the discoveries and improvements in medical science which have taken placo during the past year. $\Delta s$ this work is so ably and so admirably performed by the medical literature of the day, I shall spare you the pain of any fecbler essay in this department.

To one great movement, prcgnant either with good or evil, which is now going on, 1 would for a few moments earnestly direct your attention. Should the remarks which I make appear distasteful to some and inconclusive to others, $I$ hope that all who hear me will do me the justice to believe that I hold my opinions in all good fuith and in the sincere wish that our profession may be permanently advantaged. The subject to which I refer, relates to the recent proceedings of the different medical corporate bodies of this country. I shall not enter upon the invidious task of questioning the wisdom or policy of such bodies granting degrees or licences to practise after but slight examinations, and without the necessity of a university curriculum; as I an quite willing to believe that all who have availed themselves of the privilege, could most creditably bave passed through a far more trying ordeal. I leave it for time to show whether this merging of distinctions of rank in our profession will be as productive of good as you will, I am sure, most anxiously desire. It is to another pliase of this great question that $I$ would turn your attention.

Counected, as I am, with one of the largest provincial hospitals in the kingdom, and being lrought so immediately in contact with the rising generation of medical men, I naturally feel an interest in their education. I cannot avoid thinking that for the masses there is too great a tendency to fix the standard of book-learning too high. I feel that in consequence thereof, hospital attendance is fur too much neglected for the class-room.
The present plan would be all vary $\mathbf{w}$ ell if the licenaing bodies had simply to legislato for the larger towns or for refined and literary society. But, gentlemen, our villagee, rural and commeroial, must surely not be forgotten; and if a medical student require that high finish and polish of education, I for one am convinced that a residence as practitioner in such villages, would for such requirement be simply iutolerable. If this very enlarged literary education be absolutely necessary for a medical man, then by all means let us have it; but it may possibly be thought by some that experience teaches us otherwise. Many very illustrious medical men of England have known no language beyond their vernacular tongue, and have possessed fow attainments beyond that of a knowledge of their profession. Gentlemen, I am very far from adrocating an im. perfect education. All I want is this, that the licensing bodies should take into consideration that the whole of the United Kingdom is to be supplied with medical men, and not simply the larger towns; and that, as we have done away by legislation with the evils of unlicensed practice, the greatest care should be taken that the poor are not neglected nor oppressed.

I cannot but think that if we had gradations of rank made dependent upon ordeals of varying grades of sererity, the evil which I foresee would be avoided. I am sure you will all bear witness to this fact, at least, that in the provinces we find medical men of the older school possessing an energy of character, an acumen of intellect, a nice diagnostic discrimination, a promptness of action, and an indomitable perseverance, which, I think, we can hardly expect to find surpassed by a race of practitioners of more literury attainments.

Standing, as I do, in that city where provincial medical education took its rise, and a cotemnorary too with those who originated the scheme, some of whom are still amongst us, I naturally enough revert in thought to this most important sub. ject. Not being myself directly connected with a provincial school, I feel that I can without indelicacy express this my firm conviction, that whatever evils may be incident to such schools, they are not so great as those attached to the old system of centralisation of education in the metropolises, where there was no collegiate system, and where students were left exclusively to thernselves. I will not press this question at any greater length on your notice, gentlemen; but knowing the large influence which you collectively have, I could not let the opportunity escape of adverting to a subject which has such important bearings.

I conld wish that our profession might have honours for those who are candidates for literary as well as for professional fame; but $I$ think there is an evil in making the standard of book-learning too high for the general profession; and I cannot help fearing, from: what I have myself witnessed, that the higher you raise the book standard for the whole of the pro. fession, the more you exclude the student from the hospital, the less practical you make the medieal men.

Although it may seem a little beside my purpose, I cannot refrain from expressing this my fervent wish, that every large town in England possessed so noble an institntion as that of Owen's College in Manchester, where subjects of the greatest importance are most efficiently taught by most learned men. It is a regret to $\mathrm{me}$ that that institation is not brought into closer relationship with the medical profession in this district; and I would earnestly press, and I would do all in my power, to induce medical students to avail themselves of the advantages it so largely affords.

I am glad to find that at Cambridge there is a scheme de. vised, and at present carried on, which I think will be productive of great good to all such as claim to be candidates for literary as well as for professional fame. In days gone by, the academic course of the Cambridge University almost precluded the possibility of a general practitioner availing himself of its advantages, partly owing to the length of time required, and partly owing to the incidental expenses.

The pages of the Joursar have lately made sou acquainted with the proposed establishment of a medical hostel by Dr. Humphry of Cambridge. This scheme, I feel persuaded, is calculated to excrcise a most important influence upon the future of cur profession. The educational requirements of the University, the College of Surgeons, and the Apothecaries' Society, will thus to a considerable extent be harmonised, and that, too, without involving any loss of time or much additional expense to the student. And surely the opportunities thus afforded him of competition for university honours and prizes, and his association with members of the varions classes of society who resort to the university, must result in his mind receiving a certain amount of that training in exact science 